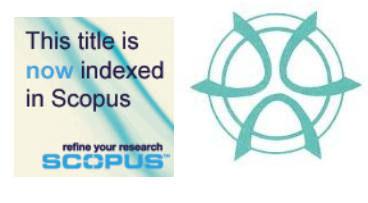

PLANNING MALAYSIA:

Urban Planning and Local Governance

Volume III (2014), Page 15- 26

\title{
SUSTAINABLE GOVERNANCE IN RELATION TO THE FINANCIAL ASPECT IN MANAGING COASTAL AREAS: MALAYSIAN EXPERIENCE
}

\author{
M.Zainora Asmawi ${ }^{1}$, Lukman Hakim Mahamod ${ }^{2}$, Mohd Zin \\ Mohamed $^{3}$ and Tuminah Paiman ${ }^{4}$
}

\author{
${ }^{1,2,3 \& 4}$ Kulliyyah of Architecture and Environmental Design \\ INTERNATIONAL ISLAMIC UNIVERSITY MALAYSIA
}

\begin{abstract}
Managing natural resources sustainably is essential in this contemporary era of land use planning system. This includes managing and planning the invaluable of coastal areas. In this regards, coastal management programmes have been regarded as a key approach in delivering the coastal strategies and objectives towards achieving a sustainable coastal development worldwide. This is supported by the good governance to ensure that the implementation of coastal development is successful. As such, this paper suggests that the aspect of good governance as one essential element of coastal management that can and should make a substantial contribution to planning and managing coastal land uses in Malaysia. It has many positive implications to the environmental, social and economic sectors. The experience of Lembaga Urus Air Selangor (LUAS) in managing the coastal areas via the implementation of good governance indicates the requirement of good governance in ensuring a successful coastal management. In addition, financial element has become a significant attribute in implementing coastal management initiatives. This study offers input in planning literatures by addressing the integration of coastal management, good local governance, land use planning and financial elements which are very relevant with today's current global changes on environment as a whole.
\end{abstract}

Keyword: governance, coastal management; financial; town planning; land use; sustainable.

${ }^{1}$ Associate Professor at KAED, IIUM, Malaysia. Email: zainora@iium.edu.my

${ }^{2}$ Assistant Professor at KAED, IIUM, Malaysia. Email: lukmanh@iium.edu.my

${ }^{3}$ Associate Professor at KAED, IIUM, Malaysia. Email: zin@iium.edu.my

${ }^{4}$ Postgraduate Student (Master). Email: tuminah01@gmail.com 
M.Zainora Asmawi, Lukman Hakim Mahamod, Mohd Zin Mohamed and Tuminah Paiman

Sustainable Governance in relation to The Financial Aspect in Managing Coastal Areas: Malaysian

Experience

\section{INTRODUCTION}

Speed is an important measure to evaluate safety of the road network. Speed is also an important transportation parameter because other than safety, it relates to time, comfort, convenience, and economics. According to Currin (2001), high speed carries high risk, whereas low speed is relatively safe. Traveling at a speed more than the speed limit is not recommended, as it could cause the drivers to lose control of their vehicles and cause fatalities, especially at winding roads. In Malaysia, accidents on roads are linked with the problem of inconsistencies in the operating speed. Driving at above the speed limit, uncertain weather conditions and drowsiness of the drivers are the three main causes of fatal accidents during the festive seasons (The Sun, 2009). A number of issues may be relevant with respect to the road safety aspect of a development proposal and in particular speed of vehicles. A study by Moore et.al, 1995 has documented an extraordinary strong association between speed and road traffic crash risk, the odds ratio for speed in excess of $84 \mathrm{~km} /$ hour is being almost 40 times higher than that for speeds below $60 \mathrm{~km} /$ hour (Petridou and Moustaki, 2000). A number of research has shown that the safest groups are the vehicles travelling at or below the $85^{\text {th }}$ to $90^{\text {th }}$ percentile speeds. A research by Elvik, et.al, 2004, has found that there is a very strong statistical relationship between speed and road safety and it is difficult to think of any other risk factor that has a more powerful impact on accidents or injuries than speed. The statistical relationship between speed and road safety is very consistent as when speed goes down, the number of accidents or injured road users also goes down in $95 \%$ of the cases. When speed goes up, the number of accidents or injured road users goes up in $71 \%$ of the cases (Elvik, et.al, 2004).

The U.S. Federal Highway Administration in 2005 has declared that nearly $30 \%$ of fatal vehicle collisions every year in the United States were taken place on curve alignment of the roads. About $83 \%$ of these crashes on winding roads were due to roadway departures from sliding, skidding or rolling over. All the causes, as mentioned above, for the vehicles which are running off the road namely sliding, skidding and rollover were caused by negotiating the curve at a very high speed. On the other hand, in Denmark, about $20 \%$ of all personal injury accidents and $13 \%$ of all fatal accidents were occurred on curves in rural areas; and in France, over $20 \%$ of fatal accidents on dangerous curves in rural areas (Herrstedt and Greibe, 2001). 
The reason for the accidents is the same as indicated earlier, where the drivers were negotiating the curve at a very high speed. In China, according to the accidents database by the Chinese Ministry of Transportation in 2009, 26,292 road accidents were occurred on curved roads accounting for about $10 \%$ of the total accidents in 2008. Additionally, 9,070 people were died and 36,112 people were severely injured in these accidents. The main cause of these accidents, again, is due to excessive vehicle speed (Chen et.al.). In a simple sense, these kinds of accidents were happened at road curves because of inappropriate speed of vehicles, traveling at a speed higher than the speed limit along that particular road. However, the inappropriate-speed theory can be applied to straight road as well, where drivers have the tendency to press the accelerator and generally increase the speed because of a greater feeling of well-being and sense of familiarity of the road, consequently increasing the accident risk. A survey conducted by Collins (2008) has identified, drivers, on average, would drive faster on a straight open road, followed by a straight road in bad weather, a bendy open road, a bendy road in bad weather, a straight road in the dark and, finally, a closed bendy road. Nonetheless, it is also shown that speed limits, if suitably selected, can help to reduce the speeds thus reducing the accident rates (Hobbs and Richardson, 1967).

In a nutshell, it is evident that there is a clear relationship between changes in speed and changes in road safety: the larger the change in speed, the larger the impact on accidents or accident victims. In relation to this statement, it can be seen that road geometrical design also has some influences towards the speed of vehicles, thus explaining about the close relationship between road geometrical design, speed, and road safety. This paper focuses on the relationship between speed of vehicles and road geometrical design, and explains how different road geometrical design can influence the speed of vehicles. This paper describes the measurement of speed characteristics of the vehicles at a specified location under free-flow traffic conditions prevailing at the time of the study. 
M.Zainora Asmawi, Lukman Hakim Mahamod, Mohd Zin Mohamed and Tuminah Paiman

Sustainable Governance in relation to The Financial Aspect in Managing Coastal Areas: Malaysian

Experience

\section{LITERATURE REVIEW}

\section{Spot Speed}

In moving traffic stream, each vehicle travels at a different speed. Thus, the traffic does not have a single characteristic value, but rather a distribution of individual speeds. Speed is generally qualified according to three main types: i) Spot speed, ii) Running speed, and iii) Journey speed.

Spot speed is speed at a certain spot on one part of road at certain time (Mohamed, 1993), defined as the average speed of vehicles passing a point. Spot speed study is designed to measure the speed characteristics at a specified location under the traffic and environmental conditions prevailing at the time of the study. According to Khanna (2001), spot speeds are affected by physical features of the road for example pavement width, curve, sight distance, gradient, pavement unevenness intersections, and roadside developments. Other factors that could influence spot speeds are environmental conditions (like weather, visibility), enforcement, traffic conditions, driver, vehicle, and motive of travel.

The above statement is supported by Hobbs (1967), where he wrote that measurements of spot speeds show a wide distribution and many interacting circumstances serve to determine the particular speed which individual drivers adopt. These circumstances will include those peculiar to the driver himself (such as his psychological and physiological traits); those concerned with his immediate environment and those affected by the more remote environmental considerations of law enforcement, type of district, and public opinions. Mohamed (1993), Khanna (2001), and Hobbs (1967) further explained the main elements of immediate environment are type of vehicle, road alignment, cross section and surface, weather, speed limits, and volume. As we can see, there are several elements that are repeated, which shows that the authors have agreed on the common elements that could influence spot speed.

Mohamed (1993) and Garber (2001) have cited that spot speed data can be used for certain purposes. It includes, but not limited to: 
a. Establishment of parameters for traffic operation and control and determination of existing roadway speeds, such as speed zones, speed limits (85th percentile speed is commonly used as the speed limit on a road), passing restrictions, and prioritisation of speed enforcement locations;

b. evaluate the effectiveness of speed enforcement programs such as use of different speed limits for passenger cars and trucks;

c. evaluate, identify or determine the adequacy and speed impact of roadway geometric characteristics, including horizontal and vertical alignment and general roadway features;

d. identify whether the roadway is in need of greater law, enforcement, or reconstruction;

e. determine speed trends and impact of traffic control devices (traffic signs, pavement markings, signals etc.);

f. evaluate the effects of speed on highway safety through the analysis of crash data for different speed characteristics; and

g. provide evidence to support or refute complaints of excessive speed.

In conducting the spot speed study, the suitable place and time for conducting this study are the important elements to be considered. According to Mohamed (1993), before placing the equipment and enumerators, researchers should search for a suitable site to conduct the study. Based on the objectives of the study, among the sites that are often selected as study site are highway or road that is straight, even and wide; road segment that is located between two junctions in urban area; road accident site or area where signboard is proposed. In terms of the suitable time to conduct the spot speed study, Mohamed (1993) has suggested the time between 9.00 a.m. to 12.00 noon; 3.00 p.m. to 6.00 p.m.; and 8.00 p.m. to 10.00 p.m.; study duration of one hour and; at least 50 vehicles as samples. 
M.Zainora Asmawi, Lukman Hakim Mahamod, Mohd Zin Mohamed and Tuminah Paiman

Sustainable Governance in relation to The Financial Aspect in Managing Coastal Areas: Malaysian

Experience

\section{Road Geometrical Design}

Ashley (1994) and Khanna (2001) stated that the required geometric design of highway depends on the speeds that vehicles are traveling. The speeds that are anticipated on the road are generally the basis for planning appropriate road alignment. Therefore, during the design stage, appropriate speed along the highways shall be determined in advance. However, Hong and Oguchi (2005) provided a contrast view stating that speed of traveling vehicles is dependent upon the geometric design of the highways. These statements highlight that both road geometrical design and speed of the vehicles have symbiosis relationship - i.e., both dependent upon each other. Ashley (1994) also stated that the geometric design parameters of horizontal alignment such as bends and straights should fit the functions of road. It was considered that straight roads are the safest and most beneficial of all but subsequently the opinion has shifted towards horizontal curvature can be beneficial as well, provided it is designed appropriately. An example of this is the introduction of bends in highway to reduce speeds, as long straight stretches of road may encourage undesirably high speeds whilst also contributing to loss of concentrations due to monotonous alignment.

It is important to note that, when assessing the acceptability of the geometry of an existing highway, the design standards related to the 85th percentile speed should be relevant. For example, if a highway has a speed limit of $90 \mathrm{~km} / \mathrm{h}$, but it is considered that the actual 85th percentile speed is greater than $90 \mathrm{~km} / \mathrm{h}$, then the required geometry should be assessed in relation to the higher observed design speed. It should always be remembered that the underlying factor for the standards of road geometry is highway safety (Ashley, 1994). Consequently, the vehicles observed in the lower 15 percent are considered to be traveling unreasonably slow and those observed above the 85th percentile value are assumed to be exceeding a safe and reasonable speed (Texas Department of Transportation, 2012).

In this regard, road geometry shall be designed to suit the needs of it, and speed is one of the main elements that must be taken into consideration as road geometry and its design influence speed. Currin (2001), Ashley (1994) and Hobbs (1967) agreed that speeds may vary, but it depends on several factors that might affect it such as: 
a. general variables - time, date, weather conditions, highway classification, lighting conditions etc.

b. road users - drivers, journey purpose, travel mode etc.

c. vehicles - type, make, year, vehicle conditions, external and internal features etc.

d. road environment - traffic control, traffic conditions, road design features, road surface, adjacent land use, special consideration etc.

On the subject of traffic lane, both Bateman (1948) and Khanna (2001) agreed that the minimum width of traffic depends upon the width of the motor vehicles and lateral clearance between passing vehicles which is considered safe. Mannering (2005) also mentioned that when lanes are narrower, adjustment is needed because narrow lanes and obstructions close to the travel lane could cause the traffic to slow as a result of reduced psychological comfort and limits on driver maneuvering and accident avoidance options.

\section{Highway Functional Classification}

Highways are classified according to their respective functions and in terms of character of the service they are providing. Highways and streets are primarily described as rural or urban roads, depending on the areas in which they are located. This primary classification is essential since urban and rural areas have different characteristics, especially those that are related to type of land use and population density, which significantly influence travel patterns (Garber, 2001). Garber (2001) also mentioned that all highway systems involve a hierarchical classification by the mix of access and mobility functions provided. There are four major classes of highways which include:
a. Limited-access facilities
b. Arterials - principal arterials and minor arterials
c. Collectors - major collectors and minor collectors
d. Local roads and streets 
M.Zainora Asmawi, Lukman Hakim Mahamod, Mohd Zin Mohamed and Tuminah Paiman

Sustainable Governance in relation to The Financial Aspect in Managing Coastal Areas: Malaysian

Experience

For this study, only literatures related to arterial system are focused in this section. Arterials are the surface facilities that are designed primarily for through movement but permit some access to abutting land (Roess, Prassas. and McShane, 2004). One of the most significant characteristics of arterial roads is vehicles traveling at a speed 80 to $90 \mathrm{~km} / \mathrm{h}$. As listed by Garber (2001), arterials can be divided into two: major or principal arterials and minor arterials. The principal and minor arterials then can be divided into two more categories namely - for principal: urban principal arterial system and rural principal arterial system, and for minor, urban minor arterial system and rural minor arterial system (Garber, 2001). Urban principal arterial system is the system of highways serves the majority activity centers of the urban areas and consist mainly the highest-trafficvolume corridors. On the other hand, the rural principal arterial system consists of a network of highways that serves substantial number of interstate trips. Virtually all highway trips between urbanized areas and a high percentage of the trips between small urban areas are made on this system.

The urban minor arterial system includes streets and highways that are interconnect with and augment the urban primary arterials. This system serves trips of moderate length and places more emphasis on land access than the primary arterial system. As for the rural minor arterial system, Garber (2001) stated that this system of road boosts the principal arterial system in the formation of a network of roads that connects cities, large towns, and other traffic generators, such as large resorts. Travel speeds on these roads are normally higher than principal arterial system.

\section{OBJECTIVES AND RESEARCH METHODOLOGY}

\section{Objectives}

The following are the objectives of this study:

i. To identify existing road geometrical design elements of straight and curved arterial road segments.

ii. To evaluate the effects of road geometrical design of the selected road stretches on the speed of vehicles.

iii. To compare spot speed of traffic stream at the selected road stretches.

iv. To suggest measures in achieving stipulated speed limit by the road users. 
PLANNING MALAYSIA

Urban Planning and Local Governance

\section{Background of Study Area}

The study area is a stretch of an arterial road namely KL Middle Ring Road (MRR2). MRR2 is a ring road that was built by Public Works Department to link neighborhood areas around Wilayah Persekutuan Kuala LumpurSelangor border. The spot speed survey station was located at two points as indicated by point $\mathrm{A}$ and Point $\mathrm{B}$ in figure 1. Point $\mathrm{A}$ is located at the curvature stretch of the road near Zoo Negara, and point B at the straight stretch of the road near a Petronas Petrol Station. Both points have the same road characteristics having three lanes in each direction measuring $3.5 \mathrm{~m}$ lane width and $10.5 \mathrm{~m}$ total width. The stretches of the selected road were dual carriageway and the road surface was asphaltic concrete.

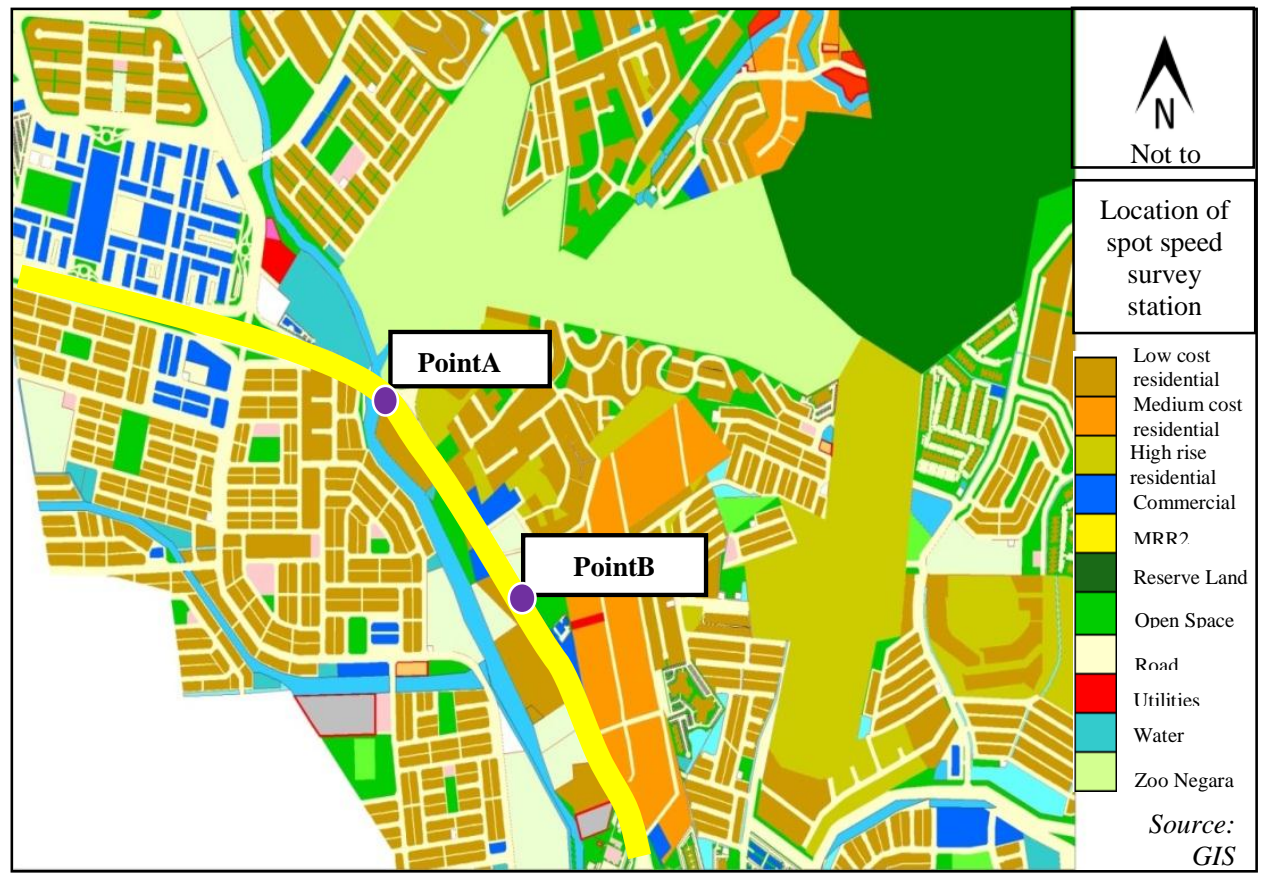

Figure 1 Location of Spot Speed Survey Statio 
M.Zainora Asmawi, Lukman Hakim Mahamod, Mohd Zin Mohamed and Tuminah Paiman

Sustainable Governance in relation to The Financial Aspect in Managing Coastal Areas: Malaysian

Experience

\subsection{Sample Size and Sampling Method}

The geometric design elements covered in this study include the horizontal curve, width of the road, and available lanes. Besides, the other physical aspects such as the width of road median, width of road shoulder, and road surface were also considered. On the other hand, the spot speed survey was conducted on 100 vehicles (which is the selected sample size) passing at a point at each of the straight and curved road.

Systematic sampling method was applied to ensure that the samples were appropriately selected to represent the population. Only passenger cars were selected as the target vehicle because they represent the predominate mode of transportation along the selected road and other roads. The systematic sampling method was applied by selecting the first vehicle randomly and then every $5^{\text {th }}$ vehicle until the total sample size was reached. On average, the traffic volume on MRR2 was 180,000 to 200,000 vehicles per day (Ministry of Works, 2011). Data was collected during off-peak hour to measure the actual speed of vehicles during free-flow traffic.

\subsection{Method of Data Collection}

Data on roadway geometry such as horizontal curve, available lanes of the selected arterial road and road surface was observed. Pictures were taken to represent data on these elements by using a camera. Furthermore, the width of the road and its shoulder were measured using a laser distance meter device and a measuring tape. To measure spot speed, two points on the arterial road, one at the straight stretch and another at the curvature stretch were selected. In order to collect the data on spot speed, the enumerators have placed a radar gun at an appropriate location at the road side at a distance of minimum 10 meter from the selected vehicles. The radar gun was targeted at each selected vehicle to measure the spot speed of the vehicles.

\subsection{Method of Data Analysis}

The spot speed characteristics such as mean, median, standard deviation and percentile speed were calculated by using statistical analysis methods. T-test was used to test the statistical differences in mean speed of the vehicles at straight and curved stretch of the road. The calculation of t-test was conducted by using Minitab. Samples, mean, and standard deviation were filled in into Minitab prior to the calculation of the t-test. 
PLANNING MALAYSIA

Urban Planning and Local Governance

\section{RESEARCH FINDINGS}

\subsection{Road Geometrical Design Analysis}

The road geometrical designs such as width and number of lanes were similar at the both selected road stretches. The width of the road is 10.5 meter with three lanes each direction, each measuring 3.5 meter wide. The width of this road is identical with that of the guideline requirements of an arterial road width (Ministry of Works, 2011).

For straight road, the width of each traffic lane is even. The road shoulder at the extreme left of the road is measured as 1 meter wide. The width of landscape and drainage reserve is 2.75 meter and 1.5 meter respectively (table 1). The median width of this road is 2.5 meter.

Similarly, the width of the curved road is also even for each of the three traffic lanes. The median is 2.5 meter wide. The width of landscape and drainage reserve is also 2.75 meter and 1.5 meter respectively. However, this road stretch has wider shoulder at approximately 3 meter. The normal, usable shoulder width that should be provided along arterial road is 3 meter (Ministry of Works, 2011).

Although both road stretches have no grades or vertical curvature, road with curvature, however, has superelevation. According to Ministry of Works, the maximum superelevation ratio that should be allowed for urban roads is 0.06. Generally, the main differences between the two road stretches are horizontal curvature, width of shoulder and superelevation (table 1). Other than that, the road stretches are similar in terms of road geometrical design. 
M.Zainora Asmawi, Lukman Hakim Mahamod, Mohd Zin Mohamed and Tuminah Paiman

Sustainable Governance in relation to The Financial Aspect in Managing Coastal Areas: Malaysian

Experience

\section{REFERENCES}

Allmendinger, P (2002). Planning theory. New York: Palgrave.

Berke, Philip. Godschalk, D (2009), Searching for the Good Plan a MetaAnalysis of Plan Quality Studies, Journal of Planning Literature, 23(3), 227-240 